\title{
Innovative technological paradigm-based approach towards biofuel feedstock
}

Jiuping $\mathrm{Xu}^{\mathrm{a}} *$ and Meihui $\mathrm{Li}^{\mathrm{a}}$

a. Business School, Sichuan University, Chengdu 610064, PR China

* Corresponding author at: E-Mail: xujiuping@scu.edu.cn

Tel.: +86-28-8541-8522; Fax: +86-28-8541-5143

Abstract

Biofuels produced from renewable energy biomass are playing a more significant role because of the environmental problems resulting from the use of fossil fuels. However, a major problem with biofuel production is that despite the range of feedstock that can be used, raw material availability varies considerably. By combining a series of theories and methods, the research objective of this study is to determine the current developments and the future trends in biofuel feedstock. By combining technological paradigm theory with literature mining, it was found that biofuel feedstock production development followed a three-stage trajectory, which was in accordance with the traditional technological paradigm - the S-curve. This new curve can be divided into BFDP (biofuel feedstock development paradigm) competition, BFDP diffusion, and BFDP shift. The biofuel production diffusion velocity model showed that there has been constant growth from 2000, with the growth rate reaching a peak in 2008, after which time it began to drop. Biofuel production worldwide is expected to remain unchanged until 2030 when a paradigm shift is expected. This study also illustrates the results of our innovative procedure - a combination of the data analysis system and the technological paradigm theory- for the present biofuel feedstock soft path that 
will lead to this paradigm shift, with integrated biofuel production feedstock systems expected to be a significant new trend.

Keywords

Biofuel feedstock; Literature mining; Technological paradigm; Biofuel feedstock development paradigm; Paradigm shift

1. Introduction

Because of diminishing supplies and greenhouse gas (GHG) emissions concerns related to climate change, continuing to use fossil fuels has been seen to be unsustainable. Biofuels derived from biomass are one of the most feasible alternatives to petroleum and many countries have initiated extensive biofuel research and development programs to develop sustainable and renewable energy transportation fuels $[1,2]$. Produced from plants or organic waste, biofuels could assist in reducing both the world's dependence on oil and CO2 emissions. Additionally, biofuels have the potential to deliver at least one-quarter of the world's projected energy needs of 623 exajoules by 2035 [3], which would significantly limit the effects of climate change, create jobs in rural areas and improve energy security. Some countries, notably the United States, Austria, Brazil, and China, have made substantial developments by dramatically accelerating their biofuel technological development.

Despite the above advantages, there is still some debate about the social, economic, environmental, and technical issues related to biofuel production and utilization. Of these, the "food vs. fuel" issue has been the most discussed in biofuel feedstock 
production research [4, 5]. Although corn-based and sugar-based biofuels are promising substitutes for gasoline in the transportation sector, there are insufficient quantities available to replace the fossil fuels consumed annually worldwide. Lignocellulosic biomass has been found to be a substantial renewable substrate for biofuel production which does not compete with food or animal feed production. However this also has limitations in terms of technology even though it can be supplied on a large-scale using different low-cost raw materials such as municipal and industrial waste, wood, and agricultural residue [6]. Besides the above mentioned biofuel feedstocks, cellulosic plants, corn stover and algae are regarded as the most promising feedstocks for the next biofuel generation.

The research objectives aim to discover the current and future biofuel feedstock developments through a combination of theories and methods on biofuel production feedstock conditions, for which no systematic analytical framework has yet been developed. Further, much of the previous research in the related fields has lacked integrity and universality, so there is a need to explore biofuel production feedstock development so as to allow for an extension to other new renewable energy feedstocks.

To focus on feedstock use for biofuel production, a data analysis system (DAS) was created based on bibliometrics and certain mining methods to allow for a comprehensive literature analysis to determine whether the focus trends, as expressed by the keywords, were in accordance with the paradigm theory first defined by Kuhn [7], was a typical example or pattern of something. Dosi later proposed the 
technological paradigm to solve economic problems using solutions based on natural science principles, which became a classic concept in innovation and technological change literature [8]. Similar to the gradual evolutionary process of life, the technological paradigm also evolves under the driving forces of market demand and industrial competition [9]. Through paradigm theory and a literature analysis, three phases were identified and a biofuel feedstock development paradigm (BFDP) was proposed to describe the evolution and provide a method for an investigation of past trends a prediction of future possibilities [10, 11, 12].

A biofuel production diffusion velocity model based on a logistics model is proposed here to demonstrate the biofuel production conditions and predict the feedstock development. Thomas Kuhn's paradigm shift theory argues that paradigm shifts occur because the existing paradigm no longer fits the traditional framework. According to the DAS and literature support, our contribution was to find that a soft path [13] was required to generate this paradigm shift. The soft energy path was first proposed by Lovins, which was then used for water management. However, this concept has not been used for other energy sources. Therefore, the soft path used in this paper seeks to improve the management of biofuel sources rather than merely find new technologies or sources, so offers a marked improvement on today's approaches and provides an entirely new perspective.

The remainder of this paper is structured as follows. Materials and methods are presented in Section 2, which includes the DAS and literature mining based on bibliometrics, the combination of the technological paradigm theory and literature 
mining to determine current development of biofuel feedstock, and a biofuel production diffusion velocity model to simulate and predict future trends. Results and discussion are presented in Section 3 along with the data mining results analyses, the three BFDP stages, the model results, and a paradigm shift discussion. Through an analysis of the keyword foci in accordance with the theoretical paradigmatic framework, three biofuel feedstock stages are proposed. The model results reveal a need for a new path and a paradigm shift. Combining the data mining results with the soft path, conclusions are given in Section 4 and an integrated system proposed for the coming paradigm shift.

2. Materials and methods

This section introduces the literature mining and analytical process, then discusses the combination of the technological paradigm theory with relevant paradigm theories to explore current biofuel feedstock trajectories, after which a diffusion velocity model is proposed to predict the future development of biofuels through a biofuel production simulation.

\subsection{DAS and literature mining}

Kuhn (1962) first popularized the terms "paradigm” and “paradigm shift”. Dosi (1982) investigated technological trajectories on the basis of paradigm shift and found that continuous innovation could proceed within a technological paradigm, while discontinuous innovation could indicate the initiation of a new paradigm. Many studies have subsequently proposed and applied these methodologies across various fields to seek further understanding of the paradigm and its dynamic development in 
111

112

selected fields [14]. The methodology usually used has been a bibliometric analysis of literature publication metadata and information. Several previous studies have used bibliometric techniques to analyze the status and trends in technological development [15].

\subsubsection{Keywords for forecasting}

Kostoff combined text mining and statistics for a study of scientific papers and proposed a systematic literature-related discovery method [16]. Also, citation-based analyses together with keyword analyses have been investigated. Kajikawa utilized citation analysis on SCI papers together with a clustering of citation network actors and analyzed the keywords to understand structural changes in sustainable energy [17], biomass and bio-fuels [18].

Given the increasingly fierce controversy on the choice of biofuel feedstock, energy research needs to consider a broader coverage of scientific and technological research so as to be able to make effective investment decisions on promising and emerging sources [19]. Forecasting is a descriptive approach based on retrospective data from the past to the present [20]. In this sense, to enable precise forecasting and effective road maps, policy makers and $R \& D$ managers have to understand the global trends in research and emerging technologies.

Keywords are essential to clearly identify the range within a specified boundary to provide an objective foresight definition. As a type of co-word analysis, keyword-based analysis has played an important role in understanding knowledge development dynamics [21]. Baldwin et al. mapped ethics and dementia research 
using keywords [22]. Tian et al. used the Institute of Scientific Information (ISI) database to measure scientific output in the Geographic Information System (GIS) field using keywords [23].

Keywords can be filtered out to motivate researchers to define a new research field, or can be retrieved from published research to be used as network actors. Also, by combining social network analysis and bibliometric analysis for the systematic foresight field method using a keyword-based bibliometric analysis and social network analysis, a quantitative, visual knowledge map can be obtained. Therefore, to visualize the global biofuel feedstock research structure, a data analysis system (DAS) was used to develop a keyword-network analysis of scientific publications.

\subsubsection{Data analysis system (DAS)}

Literature mining from published scientific literature is useful to discover key areas and trends [24]. To determine the relevant research foci, intensive research using popular academic search engines is conducted, after which appropriate technology and software are used to evaluate the relevant research papers [25]. In this section, the development of the DAS and the research process are described, and the visualization results given. The organization of the data analysis system (DAS) is shown in Fig. 1. The four necessary modules are on the left of Fig. 1, the center shows the specific procedures used, and the software interface diagrams are on the right. 


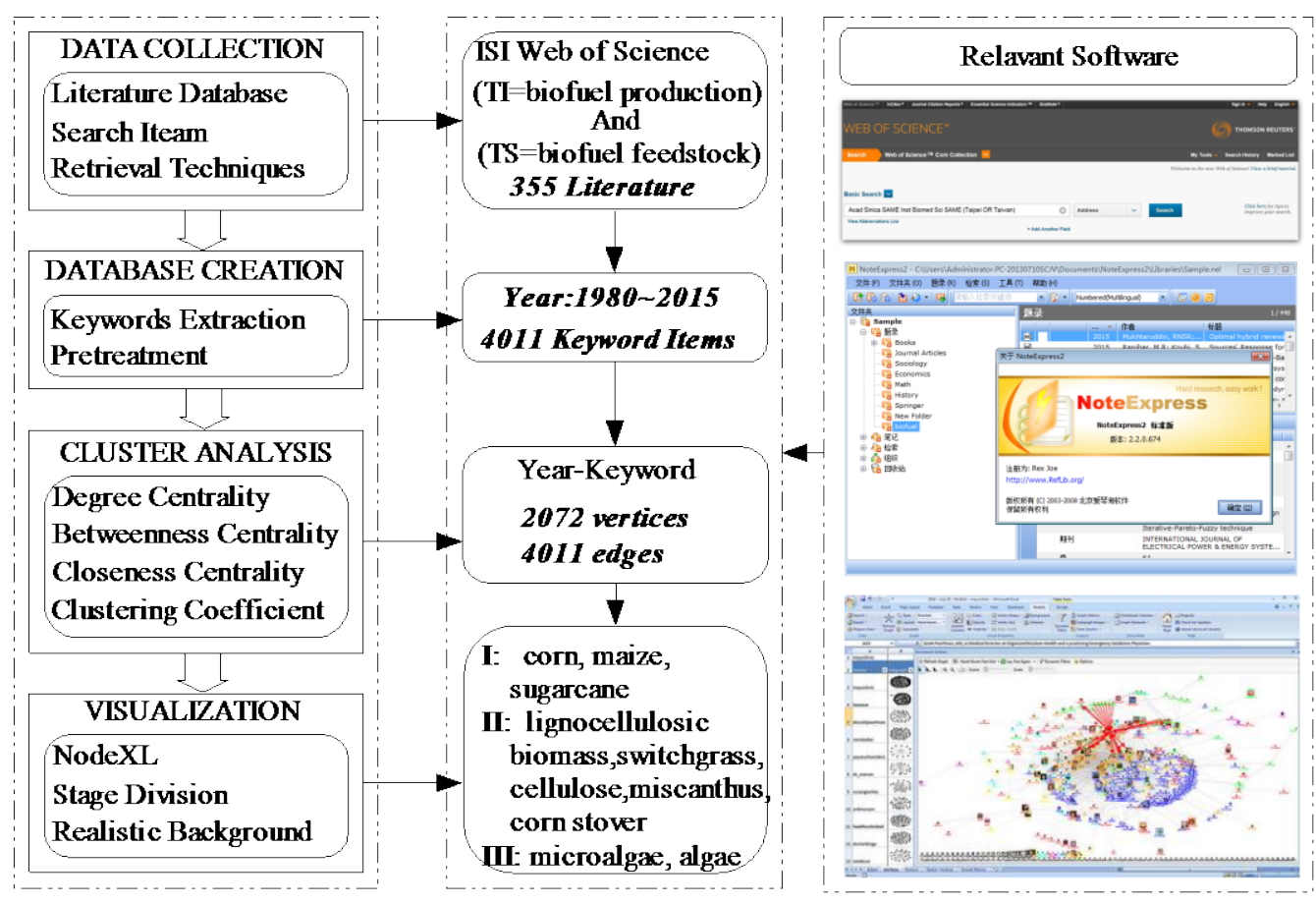

Fig. 1. DAS Literature mining

The data collection module interrogates the initial literature database to obtain the most relevant information. The ISI Web of Science was chosen as the primary database because of its powerful access to multiple research databases. Using Boolean Logic technology 374 and the search string “(TI = biofuel production) AND (TS = biofuel feedstock)" "biofuel production (feedstock)", related literature was first identified. When the search was completed, filtering to select the research field was conducted on some reselected articles to identify the specific target. Then, 355 related articles were downloaded directly to NoteExpress.

\subsubsection{Keywords foci trend analysis}

Keywords are an important index term used by authors to provide access to articles that have been published or presented in journals and databases. A key word acts as a representative focus for specific research. The keywords in the 355 related articles were extracted to create a new database to analyze the feedstock tendency. However, 
before extraction, keyword pre-treatment was conducted using the NoteExpress interface. When the articles were imported into NoteExpress and the duplicates removed, 2072 keyword items were extracted for 1980 to 2015.

NodeXL allows for a visual social network analysis of related concepts and methods through cluster analyses and visualization modules. It is a free interactive network visualization and analysis tool that leverages the widely available MS Excel ${ }^{\circledR}$ application as the platform to present generic graphical data. NodeXL imports graphical data (nodes and edge lists) into the Excel's spreadsheet from multiple social network data providers, and from these visual analyses, biofuel feedstock production development from 1980 to 2015was clearly shown. The terms 'publication year' and 'keyword' were used to form 4011 edges with 2072 vertices, a process that effectively identified and visualized the networks between the keyword and publication year nodes [26].

\subsection{Technological paradigm theory combination}

As defined by DOSI, the technological paradigm is a model and pattern of solutions for selected technological problems with specific rules aimed at acquiring new knowledge that is based on highly selective principles from the natural sciences [27]. Kuusi used a literature coupling method to identify technological bottlenecks and the technological paradigm in the field of nanotechnology for patents related to carbon nanotubes [28]. The above studies examined the technological paradigm from different aspects by selecting a scientific carrier as the research object. Therefore, the technological paradigm can also be used with previous research as the scientific 
carrier.

190 This study seeks to provide a systematic approach to an integrated trend analysis of 191 biofuel feedstock development using keywords analysis combined with the 192 technological paradigm. Although there are short-term ripples in biofuel feedstock 193 development, the long-term trends cannot escape the natural laws of growth. It is well 194 known that human and animal population growth trajectories follow a logistic curve 195 [29], also known as the S-shaped curve, which is also mirrored in the technological 196 paradigm life cycle. The S-curve is also known as a logistics curve and is used to 197 evaluate the technological growth at each stage in its life cycle and to predict when a 198 specific technology will reach a particular stage. If time is depicted on the x-axis, and 199 the technological evolution is the y-axis, then the relationship follows an ' $\mathrm{S}$ '-like 200 curve, which can be divided into three stages (competition, diffusion, shift), each of 201 which has four key phases (emergence, growth, maturity, and saturation), as shown in 202 Fig. 2 [30]. When the exponential growth encounters resource limitations, growth 203 slows and eventually reaches a level where the driving forces and resource constraints 204 are in balance. 


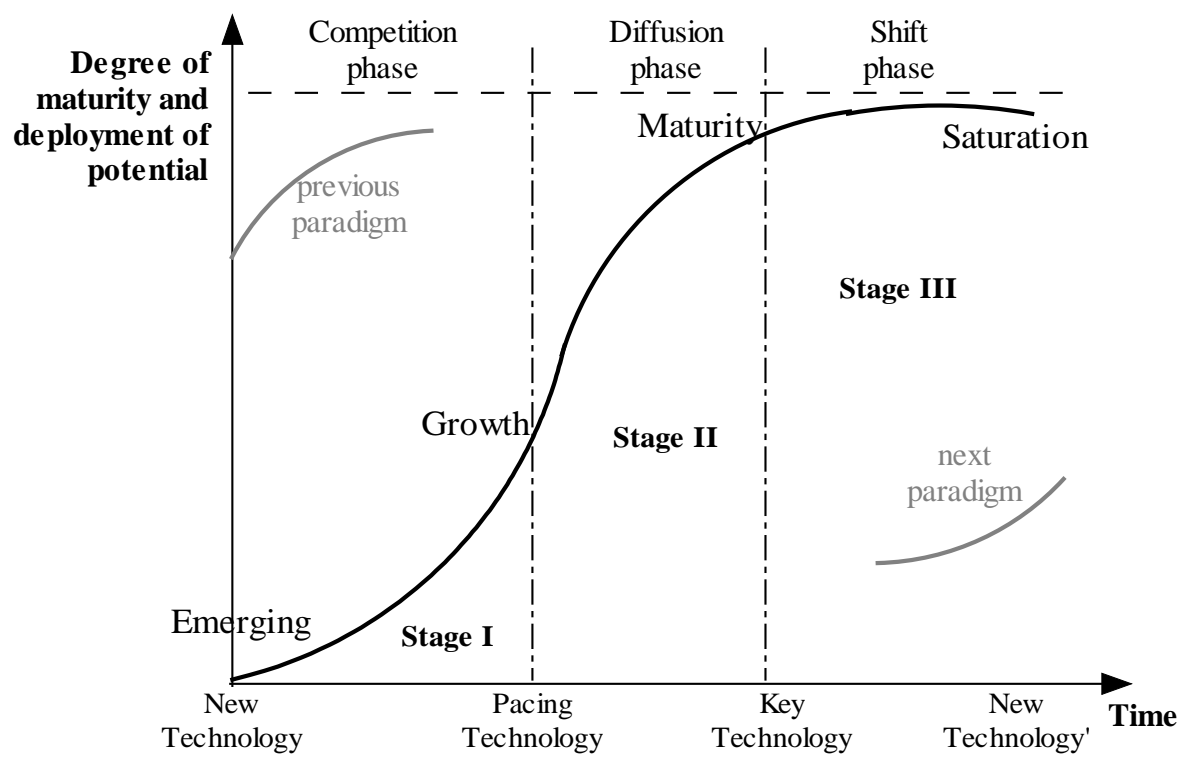

Fig.2. Life cycle of the technological paradigm-S-curve

Schilling and Esmundo [31] analyzed renewable energies using a technological S-curve perspective and identified some important implications for both governments and industry. Chen et al. [32] predicted the technological S-curves for hydrogen energy and fuel cell technologies by integrating bibliometric analysis into a logistics growth curve model. In this study, to understand the development status of each major biofuel feedstock, a classification of collected biofuel feedstock research is required. Keywords in the text provide rich information on the characteristics of a feedstock, so this information can be used to categorize the keywords and the feedstock types. Grouping the feedstock types enables a detailed examination of the growth trajectory of each biofuel feedstock. Therefore, the development trajectory for biofuel feedstock can be elucidated from the keywords linked to the relevant technological paradigm theory.

\subsection{Biofuel production diffusion velocity model}

The objective of the diffusion velocity model is to represent the level of spread of an 
221 innovation so as to depict the successive increases in the number of adopters to

222 predict the continual development of a diffusion process already in progress. A

223 diffusion model also refers to aspects of the technological diffusion model, which is

224 often used to predict the future spread of technology [33]. As the biofuels market is

225 essentially a product market, the development evolution can be estimated using a

226 diffusion equation simulation. From a macro perspective, it also evolves following an

227 initialization, maturity and barrier trajectory similar to the S-curve. Therefore, based

228 on the Logistics principle, the biofuels velocity diffusion model can be developed to

229 study its current state and then to predict future trends.

$230 \quad$ 2.3.1. Diffusion velocity model sources

By extrapolating current trends to the future, we can predict future trends and obtain a prospective perspective. Qualitative methods for forecasting include Delphi and scenarios, and for quantitative methods extrapolations of a time series of the growth curves using logistics or Gompertz functions [34] can be used. Here, the diffusion velocity model can assist in making future predictions. Researchers typically measure diffusion speed by first estimating a specific diffusion model, then using one or more parameter estimates as an indicator of the diffusion speed. As an important type of diffusion model, the velocity model, also known as the general model, macro analysis model or S-series model, considers the overall diffusion rate based on statistical analyses and reflects the process of the required time for the technological diffusion velocity, with its basic approach being curve fitting [35].

Studies in economics and the history of technology have typically used the logistics 
model. Griliches [36] and Mansfield [37] found that the growth of certain technological innovations can be represented by an S-shaped or logistics curve:

245 diffusion rates first rise and then fall over time, as shown in Fig. 2. Many studies have 246 shown that the simplest and most commonly used form has been based on the logistics model. The behavioral justification for the use of logistics in characterizing 248 the endogenous learning effects in the diffusion process is analogous to the spread of 249 epidemics in the biological sciences [38].

250 Empirical evidence for the economic, demographic and product effects on the 251 diffusion velocity model can provide decision support for managers and analysts 252 when using generalizable patterns across products to make forecasts [39]. Further, the 253 application of the diffusion S-shaped curve can be a useful tool in understanding new 254 market potential through the growth in new technologies or product categories [40].

255 To describe the diffusion production changes, biofuel production diffusion velocity 256 characteristics and existing studies were used to develop the logistics model below. 257 The rate and direction of the production change, or the production choice process, was 258 decided on as a result of the competition between the fully developed and the 259 emerging feedstock systems. Here, a diffusion model based on field theory is 260 proposed for biofuel production study.

261 2.3.2. Modeling and data collection

262 The application of a selected model to study biofuel production diffusion velocity was 263 based on a theoretical basis which states that diffusion processes follow S-shaped curves as described above. However, the diffusion model parameters needed to be 
adapted to reflect biofuel market potential, the policy drivers and the technological improvements. Therefore, managers or policy makers could use the diffusion model to assess the impact of their policies as well as to determine direction to inform the design of new renewables.

Biofuel production diffusion characteristics and existing studies were used to develop the logistics model below which describes the diffusion changes in biofuel market. The rate and direction of the feedstock choice process, or technical change, was probably decided on as result of the competition between fully developed and emerging integrated systems. Based on a logistics model, a field theory originally derived from a physics concept is introduced.

$$
\frac{d V(t)}{d t}=\gamma V\left(1-\frac{V}{V_{\text {pred }}}\right)
$$

In Eq. $1, \frac{d V(t)}{d t}$ refers to the variation in the share of specific technologies in the market at time $t, V$ is the existing market share, $V_{\text {pred }}$ represents the preliminary market occupancy, and $\gamma$ is the natural diffusion rate. When $\alpha=\gamma / V_{\text {pred }}$, the biofuel production diffusion model is derived as Eq. 2.

$$
V=\frac{V_{\text {pred }}}{1+C e^{-\alpha t}}
$$

In Eq. 2, $\mathrm{C}$ is a constant coefficient, and $\alpha$ is the self-diffusion rate, which indicates the possibility of new feedstocks or technologies. After taking the derivative of Eq. 2, the biofuel production diffusion vecity model is set in Eq. 3, where $v(t)$ within which represents the growth speed in annual biofuel production capacity. This model was used to simulate production and illuminate the diffusion velocity changes in the 

velocity $v$ represents the annual added production $(v)$. The basic data are presented

296 in Table 1.

297

Table 1. The basic data of $v$ and $V$

\begin{tabular}{cccc}
\hline Year & $\mathrm{t}$ & $\begin{array}{c}\text { Annual added } \\
\text { production } v(\text { Ktoe })\end{array}$ & $\begin{array}{c}\text { Total added } \\
\text { production V(Ktoe) }\end{array}$ \\
\hline 2000 & 0 & - & 9,179 \\
2001 & 1 & 848 & 10,024 \\
2002 & 2 & 1,811 & 11,835 \\
2003 & 3 & 2,851 & 14,686 \\
2004 & 4 & 1,759 & 16,445 \\
2005 & 5 & 3,259 & 19,704 \\
2006 & 6 & 5,972 & 25,676 \\
2007 & 7 & 9,165 & 34,841 \\
2008 & 8 & 11,661 & 46,502 \\
2009 & 9 & 5,384 & 51,886 \\
2010 & 10 & 7,866 & 59,752 \\
2011 & 11 & 1,136 & 60,888 \\
2012 & 12 & 770 & 61,658 \\
2013 & 13 & 4,270 & 65,928 \\
2014 & 14 & 4,864 & 70,792 \\
\hline
\end{tabular}

Although, the diffusion of production or technologies does not follow a single uniform pattern and is a complex phenomenon, models have been used to explain diffusion rates and to estimate the parameters or coefficients for the diffusion model equations. Biofuel production capacity refers to a thousand tonnes of oil equivalent (Ktoe). The accumulative total annual biofuel production capacity $(V)$ is introduced into the mathematical model above as an independent variable, and was taken from the Statistical Review of World Energy 2015 by BP Amoco [41]. The diffusion in Table 1.

emerging feedstocks or technologies.

$$
v(t)=\frac{d V}{d t}=\frac{C V_{p r e d} \alpha e^{-\alpha t}}{\left(1+C e^{-\alpha t}\right)^{2}}
$$




\subsection{Mining results analyses}

After Graph Metrics, Group Calculation and Graph rearrangements connected to

NodeXL, the results were displayed graphically in a network, as shown in Fig. 3. The two graphs in Fig. 3 are shown using the different Harel-koren Fast Multiscale and Circle layouts. The red and circle 'year' vertices, and the green, blue, orange and black 'keyword' vertices are displayed using different shapes selected according to the calculation index Degree (Degree $>=7$ ). The two graphs below are the same graph at different times, so illustrate the research focus keywords over three time frames: area I (green triangle), area II (green circle), and area III (green square).
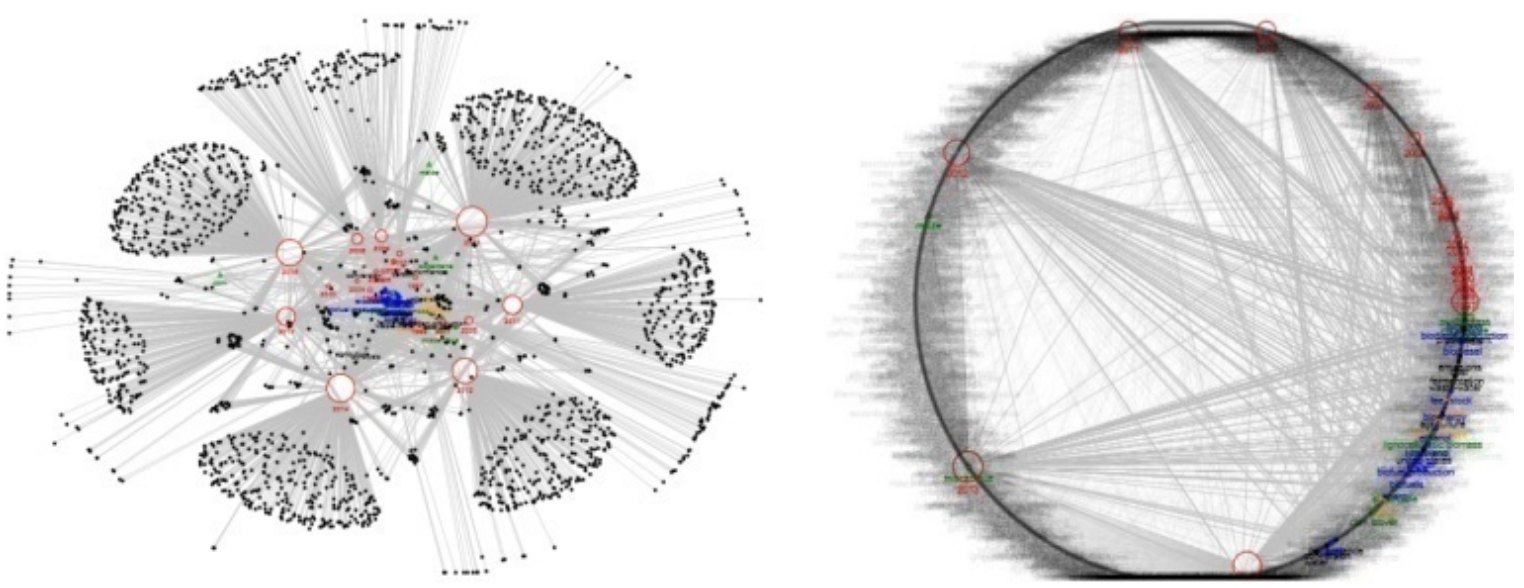

Fig. 3. Keyword focus trend analyses (The first displayed graph)

In Fig. 4, the year by year keyword trends are shown. In Area I (probably from 2002 to 2007), the keywords 'corn', 'maize' and 'sugarcane', amongst others, were the main research foci. In Area II (probably from 2007 to 2013), the keywords 'lignocellulosic biomass', 'switchgrass', 'cellulose', 'miscanthus' and 'corn stover' were the main research foci. For the more recent years from 2013 to 2015 (Area III), the only keywords found were 'microalgae' and 'algae'. 


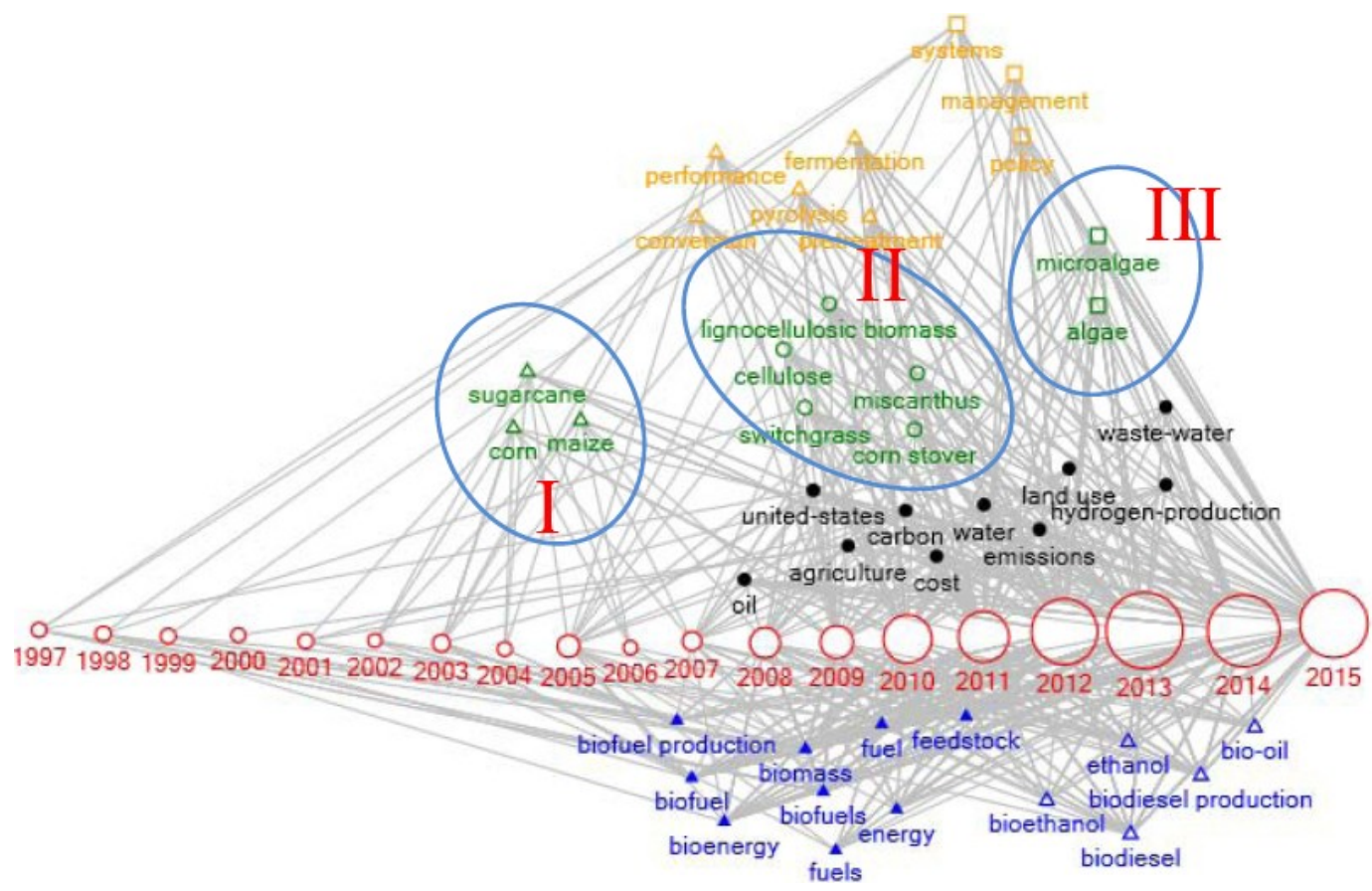

Fig. 4. Keyword focus trend analyses (“I”,” II”,” III” areas)

318 In Fig. 5, besides three areas mentioned above, some other information is displayed.

319 Below the 'year' vertices, there are several keywords (blue triangle vertexes, "B" Area) such as 'biomass', ‘energy', 'biofuels', 'biofuel', 'biofuel production',

321 'bioenergy', 'fuels', 'fuel' and feedstock', which are the main topics in this research,

322 as they are the keyword foci across all years. Other keywords (blue solid triangle

323 vertexes, "P” Area) below the 'year' vertices, such as 'bioethanol', 'ethanol',

324 'biodiesel', 'biodiesel production' and 'bio-oil', are the main products or items related

325 to these main topics. The keywords have had a consistent focus from 1980 to 2015

326 (but mainly in last ten years). 


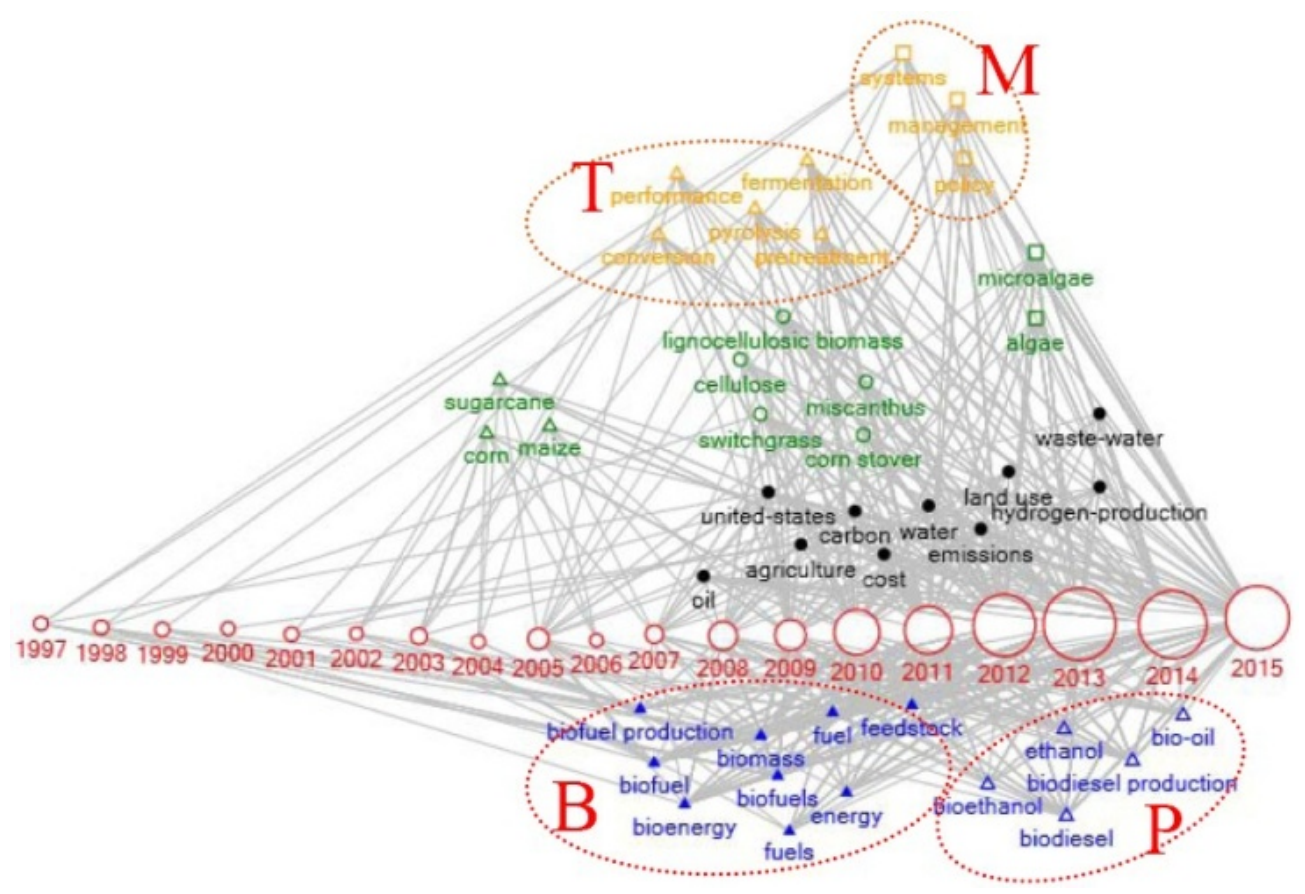

Fig. 5. Keyword focus trend analyses (“B”,’P”,’T”,’M” areas)

329 The keywords above the dotted line area (orange triangle vertices, "T" Area) show the main technologies used for the biofuel production such as 'fermentation', 'pyrolysis',

331 'pretreatment', 'conversion', and 'performance', and the others (orange square

332 vertices, “M” Area) show the relevant management items such as 'management',

333 'policy' and 'system'.

334 All keywords are summarized in Table 2.

335 Table 2. The keywords lists grouped by areas

\begin{tabular}{|c|c|c|}
\hline Area & Vertexes & Keywords \\
\hline $\mathrm{I}$ & green triangle & corn, maize, sugarcane \\
\hline II & green circle & $\begin{array}{l}\text { lignocellulosic biomass, switchgrass, cellulose, } \\
\text { miscanthus, corn stover }\end{array}$ \\
\hline III & green square & microalgae,algae \\
\hline $\mathrm{B}$ & blue triangle & $\begin{array}{l}\text { biofuel production, biofuel, bioenergy, biomass, } \\
\text { biofuels, fuels, fuel, energy, feedstock }\end{array}$ \\
\hline $\mathrm{P}$ & blue solid triangle & $\begin{array}{l}\text { bioethanol, ethanol, biodiesel, } \\
\text { biodiesel production, bio-oil }\end{array}$ \\
\hline
\end{tabular}




\begin{tabular}{ccc}
\hline $\mathrm{T}$ & orange triangle & $\begin{array}{c}\text { performance, fermentation, conversion, } \\
\text { pretreatment, pyrolysis }\end{array}$ \\
$\mathrm{M}$ & orange square & Management, policy, systems \\
\hline
\end{tabular}

\subsection{Three BFDP stages}

According above literature analysis and paradigm theory combination, a novel concept for the biofuel feedstock development paradigm (BFDP) is proposed to illustrate the feedstock development evolution, which to the best of our knowledge is a new research area. The technological paradigm is a long term, continuous process which goes through a complete life cycle from birth, growth, maturity to retirement. Each paradigmatic phase is characterized by technical solution selection and a self-structuring process which features an industrial learning of the new technical solutions [42]. This paradigmatic phase was added to describe the biofuel production feedstock evolution.

347 From the literature mining, we concluded that the feedstock for biofuel production met the laws of the paradigm and could be summarized in three stages characterized 349 by the different biofuel generations: competition, diffusion, and shift. The first generation is derived edible biomass, the second generation is derived non-food biomass and the third generation is carbon dioxide sequestration such as microalgae

352 [43]. With this analysis, we combined paradigm theory with biofuel production 353 feedstock and proposed a novel biofuel feedstock development paradigm (BFDP). 354 The three BFDP stages were identified as BFDP competition, BFDP diffusion, and BFDP shift, all of which are discussed in the following. 

next advanced technological paradigm.

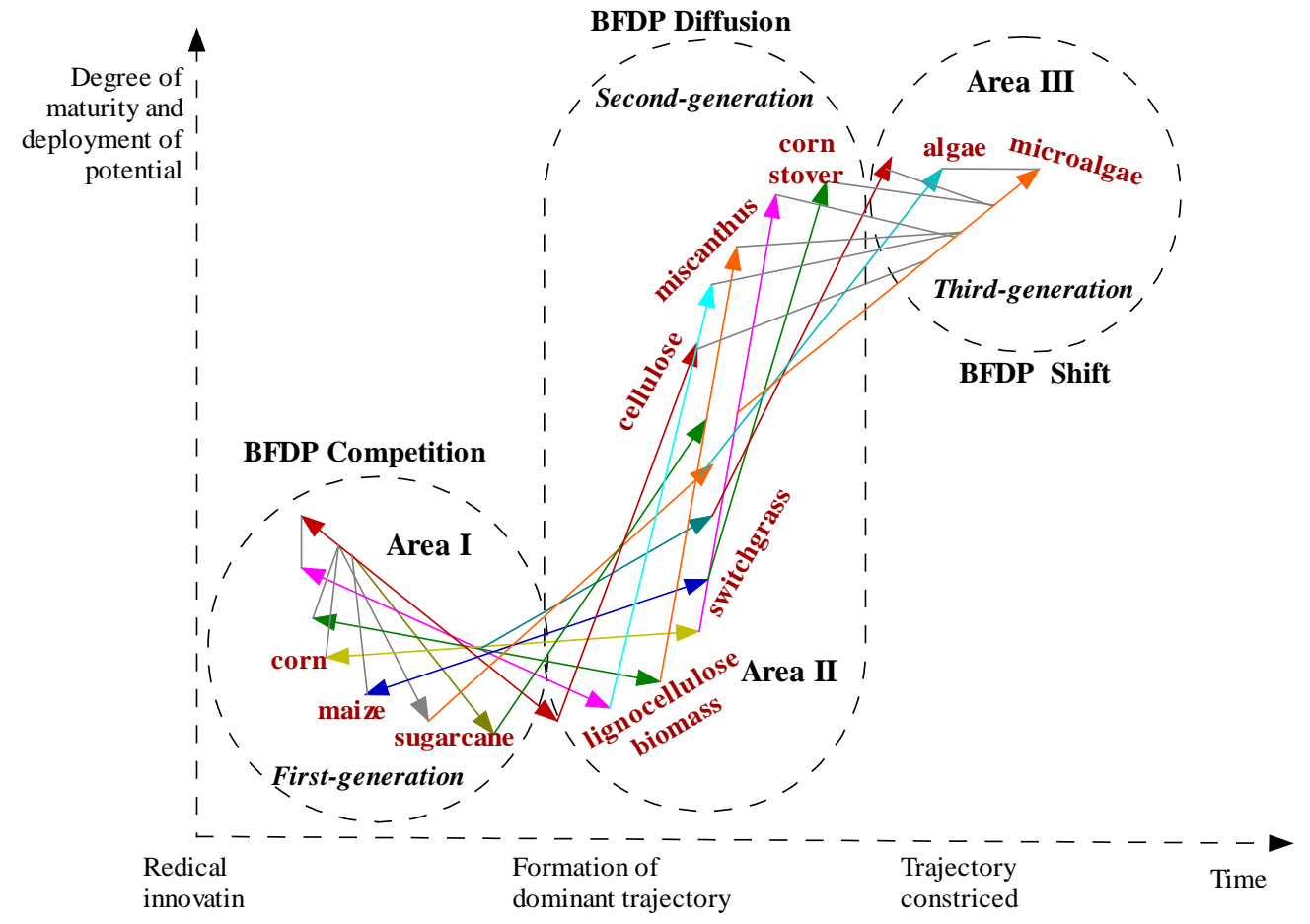

Fig. 6. BFDP evolution based on the technological paradigm

\subsubsection{BFDP competition}

From Area I, the first stage, “first-generation biofuel” was the main feedstock used for biofuel production, which included corn, maize, and sugarcane. As shown in Fig. 7, in this area, the connecting lines between the 'year' and the 'keyword' were concentrated. 
373

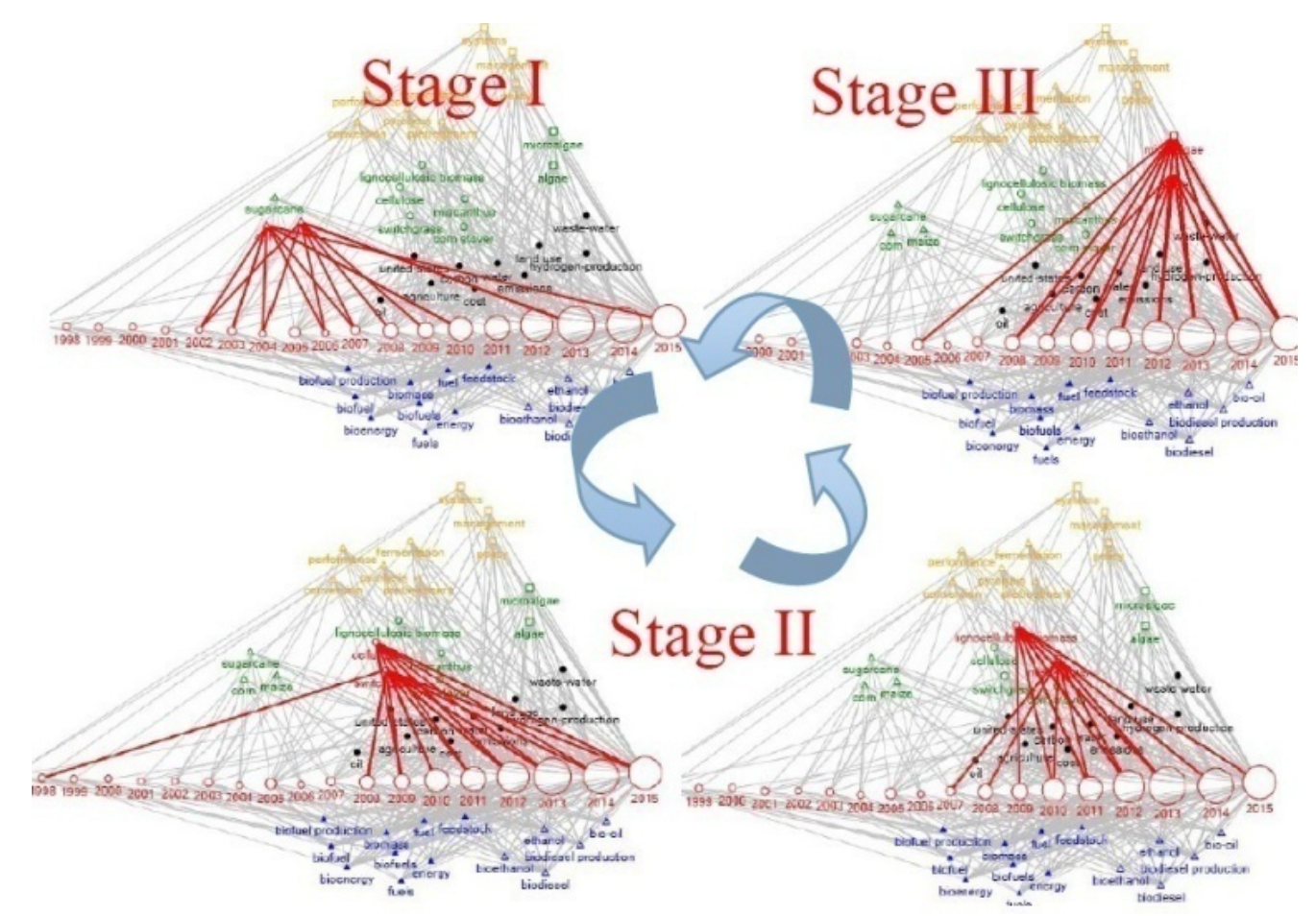

Fig. 7. Keywords focus trend analysis (Stage I, Stage II and Stage III)

Over the past few years, the demand for first-generation biofuel produced mainly from agricultural crops traditionally grown for food and animal feed purposes, has continued to increase significantly. These biofuels are derived from the starch, sugar, animal fats, and vegetable oil that these crops provide. Corn, wheat, maize, sugarcane and other starchrich crops are commonly regarded as first-generation biofuel feedstock [45]. First-generation biofuel was initially adopted as oxygenate and then as a primary transportation fuel in the United States, Brazil, Canada, and several European nations [46].

First-generation biofuel sources have GHG emission avoidance potential, can provide 
useful and valuable coproducts, and, if carefully managed, are able to support the drive for sustainable development in many developing countries. However, the potential to meet government liquid transport fuel targets for oil-product substitution, economic growth, and climate change mitigation goals is limited by the competition for the land and water used for food and fiber production [47, 48], the high production and processing costs needed to compete with petroleum products, which often require government subsidies [49], and the widely varying assessments of the net greenhouse gas (GHG) reductions once land-use change is taken into account [50, 51]. Therefore, the sustainable and economic production of first-generation biofuel has come under close scrutiny.

As mentioned above, in the evolutionary BFDP competition process, many early feedstock types emerged, which were utilized in the first-generation biofuel derived traditional food sources. The production of first-generation biofuel from these crops has increased rapidly over the past few years. As the technologies have matured, other issues have arisen, such as unsustainable production relating to deforestation, water use, and land management, the inflation of food commodity prices because of competition for food feedstock crops, and the need for generous government support schemes to remain competitive. Therefore, the perceived environmental benefits of first-generation biofuel have recently been called into question. As a result, first-generation biofuel in the BFDP competition stage has significant limitations, and hope has been placed on second-generation biofuel production [50]. Therefore, based on demand-pull and technology-push theories, market forces and technological 
innovation is expected to contribute to a new renewable energy framework in the near future.

\subsubsection{BFDP diffusion}

From Area II, the second stage, "second-generation biofuel” was identified as the main biofuel production feedstock, which includes lignocellulosic biomass, switchgrass, cellulose, miscanthus and corn stover. As shown in Fig. 7, the connecting lines between the 'year' and the 'keyword' are mainly concentrated in this area.

Because of the rising food prices and land-use problems of the "first-generation biofuels” in the competition stage, the main feedstock for biofuel production in the BFDP competition phase needed to encourage the evolution of more suitable feedstock. The paradigmatic evolution in the diffusion stage is the most important feature of these common technological innovations [52]. As market demand increased because of industrial competition, the BFDP diffusion stage gradually emerged. By combining advanced systems with intensive additional research to eliminate bottlenecks, second-generation biofuel could surpass traditional firstgeneration biofuel to become dominant in the BFDP diffusion stage [53]. Therefore, from the keyword focus trend analysis and paradigmatic evolution theory, "second-generation biofuel” is maturing and developing as a stable feedstock structure.

Second-generation biofuel, also known as advanced biofuel, are fuels that can be manufactured from various types of biomass, like crop residues, forest by-products, perennial grasses, and other forms of plant biomass that are collectively termed "lignocellulosic" [54]. Second-generation biofuel produced from non-food crops has 
been developed to overcome the limitations inherent in first-generation biofuel. Second-generation biofuel is more cost competitive with existing fossil fuels [55], and life cycle assessments of second-generation biofuels have also indicated that they can increase 'net energy gains'.

However, second-generation biofuel has its drawbacks. Production still requires land, so even plants that need minimal input compete with food crops for some resources. Further, first-generation biofuel has had a head start of more than half a century, but secondgeneration biofuel production has been estimated to take at least five to ten years to become large-scale [56]. Higher costs and technological limitations are the main contributions. For example, the complexities of saccharification are a major limitation in the conversion of lignocellulosic biomass to ethanol [57].

In summary, because of the advantages of these non-food crops, "second-generation biofuel” is playing a significant role in the BFDP diffusion stage. However, because of problems such as technological limitations, more paths need to be developed for the beginning of the next technological paradigm.

\subsubsection{BFDP shift}

From Area III, the third stage, "third-generation biofuel" is the main biofuel production feedstock, represented by microalgae and algae [58]. As shown in Fig. 7, the connecting lines between the 'year' and the 'keyword' are mainly concentrated in this area.

The technological paradigm moved into the shift phase because of the emergence of disruptive technologies [59] and technological limitations [60]. Full competition in 
specific areas led to disruptive technologies, and technological limitations began to emerge because of product demand in the market. Therefore, market demand and industrial technological competition were the main reasons for the technology shift. The BFDP shift stage occurred because of the need to guarantee land for food crops, and other environmental and societal problems [61]. A new sustainable feedstock was then developed to solve or mitigate the first and second generation biofuel production problems. As identified in the keyword analysis, the most promising biofuel feedstock in this third generation biofuel phase has been microalgae and algae.

Corn and sugarcane are currently regarded as industrial feedstocks, but the "food versus fuel” concerns preclude any long-term use. Therefore, inedible lignocellulosic plant materials became a more preferred feedstock, but microbial technologies for the fermentation of the simple sugars in the lignocellulose have yet to overcome the cost of the complex processes needed to release these sugars from recalcitrant polysaccharides [62]. Therefore, distinct strategies are required to develop scalable and sustainable nonlignocellulosic biomass resources such as macroalgae for use as the next-generation feedstock. Requiring no arable land, fertilizers, or fresh water resources, macroalgae is already being grown for human consumption, but not as a staple crop [62].

Successful microalgae-production systems are the key to the development of the third biofuel generation, as they could provide an alternative to one of the most difficult problems of large-scale biomass production deployment [63, 64]. Further, algae are the fastest growing plants on earth. Depending on processing methods, algae can be 
used to produce biodiesel, ethanol, and many other products [65].

Despite the apparent advantages of algal biofuels, significant economic, technical and environmental challenges still need to be solved to scale-up algal biofuel production. Most current algal biofuel technologies have been focused on cultivating relatively pure, highoil algal species and extracting the oil for conversion to biodiesel via transesterification. Maintaining a pure high-oil algae culture, however, is difficult [66]. Further, microalgae biomass is not yet a viable choice for commercial biofuel production due to the extensive energy inputs needed compared to current terrestrial energy crops [64]. One key practical limitation for the algal biofuel industry is the achievement of a net positive cost and an energy balance for the extraction of biofuel from wet algal biomass, and concerns about the freshwater and fertilizer needed for full-scale algal biofuel production have been raised [67]. Further, the extensive antibiotic use to ensure disease free algae cultures remains an unresolved issue [63].

However, at the current stage, microalgae biomass is still not a viable choice for commercial biofuel production because of the extensive energy inputs required compared to current terrestrial energy crops [64]. To grow algae, there are large energy requirements because of the nutrients required, and environmental sustainability challenges because of the need for large quantities of water and nutrients.

To summarize, the increasing demands placed on natural resources for fuel and food production require the further exploration of efficient, sustainable feedstocks such as microalgae or other plant sources yet to be exploited [68]. As feedstock for 
commercial-scale biofuel production, the mass production of microalgae could play a significant role in the BFDP shift stage. As discussed above, when moving into this phase, there are still difficulties to be overcome, so material sources and alternative methods need to be researched and developed. Therefore, it is important to work towards long term, effective sustainability.

3.3. Model results and thoughts

\subsubsection{Parameter simulation}

Through the simulation and calculation of SPSS, the original values for $C$ and $V_{\text {pred }}$ were assigned. The parameter for a in the nonlinear regression function was estimated using the Statistical Package for Social Science 19.0. After the simulation, $\alpha$ was found to be $0.66, C$ was 176.79 , and $V_{\text {pred }}$ was 57006.788 . The diffusion velocity model was then constructed using Eq. 4.

$$
v(t)=\frac{176.79 \times 57006.788 \times 0.66 \times e^{-0.66 \times t}}{\left(1+176.79 \times e^{-0.66 \times t}\right)^{2}}
$$

The annual added generation was first calculated as the ' pred $-v$ ' curve in Fig. 8 (the figure below). In Fig. 8, it can be clearly seen that around 2008, the biofuel production diffusion velocity had reached a peak. When $t=24$ (in 2024), the diffusion velocity is estimated at less than 1 and by 2030 , it is expected to be close to zero. The actual values for the added installation $(v)$ had a similar trend to the pred $-v$ except for the values in $2013(t=13)$ and $2014(t=14)$, which were 1170.33 Ktoe and 624.12 Ktoe. Statistics from countries that generate biofuel production can offer an explanation for these results. Data from the Statistical Review of World Energy 2015 shows that the United States and Brazil were the main growth countries in 2013 and 

increased in the United States by 1192 Ktoe, and in Brazil by 2235 Ktoe (80\% the total increment) and in 2014 increased in the United States by 1594 Ktoe, Brazil by 874 Ktoe, in Indonesia by 704 Ktoe and in Argentina by 608 Ktoe (78\% the total increment). Therefore, the simulated result affected by the external factors in Fig. 8 showed that the development of biofuel production development had a strong inertia

522 force along the S-curve. In other words, the diffusion velocity model is reasonable.

523 From equation $V(t)=V(t-1)+v(t)$, and pred $-V(t)=$ pred $-V(t-1)+$ pred $-v(t)$,

524 the global biofuel production predicted values are shown in Fig. 8 (the figure 525 above).

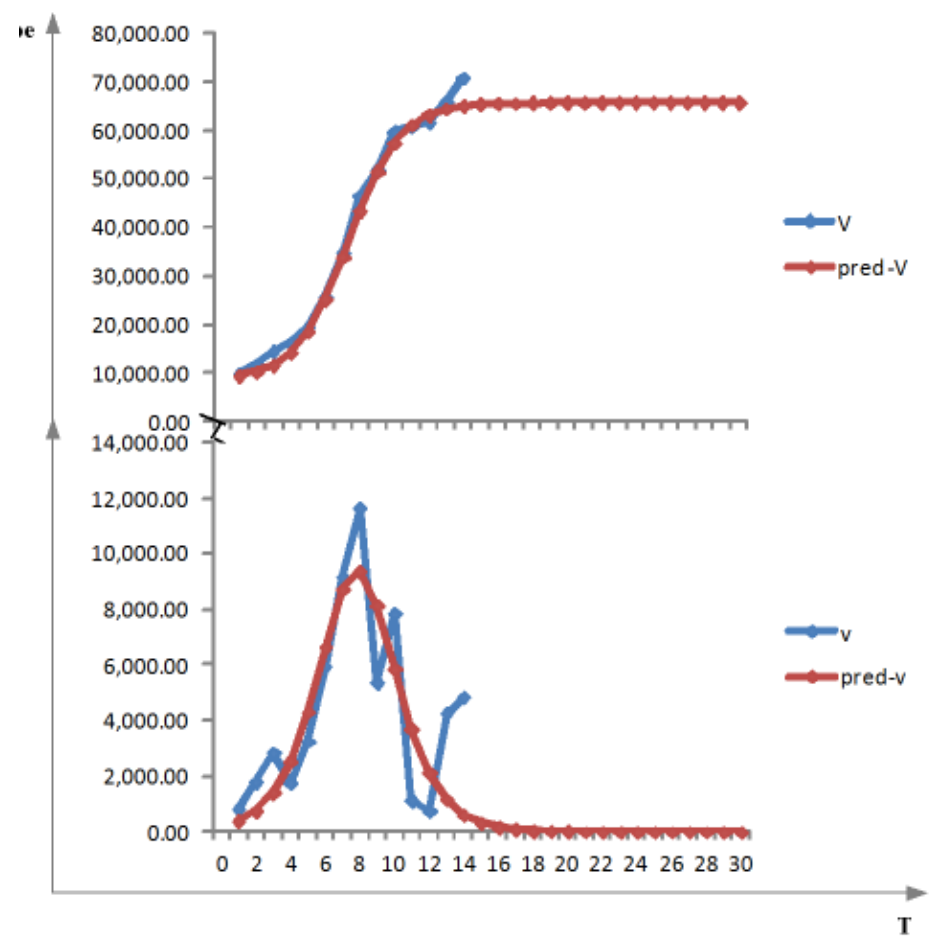

Fig. 8. Curve for $(V$, pred- $V)$ and $(v$, pred-v)

3.3.2. Model results and forecast

The specific prediction results are shown in Fig. 8. Around 2008, biofuel production 
531 the worldwide biofuel production is expected to be relatively unchanged, as can be seen in Table 3. Therefore, from 2008 to 2024, due to technical innovations, there was

533 and is expected to be a rapid development in biofuel production. However, biofuel

534 production innovations will gradually slow when the diffusion velocity addresses

535 specific levels of need.

Table 3. Actual production V and predicted production V

\begin{tabular}{cccccccc}
\hline Year & $\mathrm{t}$ & $\begin{array}{c}\text { Actual } \\
\text { production } \\
\text { V(Ktoe) }\end{array}$ & $\begin{array}{c}\text { Predicted } \\
\text { production } \\
\text { V(Ktoe) }\end{array}$ & Year & $\mathrm{t}$ & $\begin{array}{c}\text { Actual } \\
\text { production } \\
\text { V(Ktoe })\end{array}$ & $\begin{array}{c}\text { Predicted } \\
\text { production } \\
\text { V(Ktoe })\end{array}$ \\
\hline 2001 & 1 & $10,024.00$ & $9,581.90$ & 2016 & 16 & - & $65,564.61$ \\
2002 & 2 & $11,835.00$ & $10,345.88$ & 2017 & 17 & - & $65,653.34$ \\
2003 & 3 & $14,686.00$ & $11,768.34$ & 2018 & 18 & - & $65,699.31$ \\
2004 & 4 & $16,445.00$ & $14,328.66$ & 2019 & 19 & - & $65,723.10$ \\
2005 & 5 & $19,704.00$ & $18,666.31$ & 2020 & 20 & - & $65,735.40$ \\
2006 & 6 & $25,676.00$ & $25,305.66$ & 2021 & 21 & - & $65,741.76$ \\
2007 & 7 & $34,841.00$ & $34,023.16$ & 2022 & 22 & - & $65,745.05$ \\
2008 & 8 & $46,502.00$ & $43,403.39$ & 2023 & 23 & - & $65,746.75$ \\
2009 & 9 & $51,886.00$ & $51,557.11$ & 2024 & 24 & - & $65,747.62$ \\
2010 & 10 & $59,752.00$ & $57,437.30$ & 2025 & 25 & - & $65,748.08$ \\
2011 & 11 & $60,888.00$ & $61,137.15$ & 2026 & 26 & - & $65,748.31$ \\
2012 & 12 & $61,658.00$ & $63,271.34$ & 2027 & 27 & - & $65,748.43$ \\
2013 & 13 & $65,928.00$ & $64,441.67$ & 2028 & 28 & - & $65,748.50$ \\
2014 & 14 & $70,792.00$ & $65,065.78$ & 2029 & 29 & - & $65,748.53$ \\
2015 & 15 & - & $65,393.69$ & 2030 & 30 & - & $65,748.55$ \\
\hline
\end{tabular}

The reality is that in 2013 and 2014, there was an increase in production. The United

538 States and Brazil are the two largest producers and exporters of ethanol in the world,

539 with ethanol being produced from corn feedstock in the United States and sugarcane

540 in Brazil $[69,70]$. Biomass energy consumption in the United States grew by more

541 than $60 \%$ from 2002 to 2013, which was almost entirely due to increased biomass

542 consumption for the production of biofuels, and primarily ethanol [71]. 
543 With ample supplies of reasonably priced feedstocks, a blenders' tax credit, and fuel 544 industry acceptance of the product, biodiesel producers in 2013 experienced the best 545 profits since late 2011, which consequently led to a sharp increase in production in 546 2013. However, unsettled government policy issues cloud the industry's future for the 547 years ahead, which is causing uncertainty in the industry [72].

548 Also in 2000, over $90 \%$ of the U.S. corn crop went to feed people and livestock, many 549 in undeveloped countries, with less than 5\% used to produce ethanol. In 2013, 550 however, $40 \%$ went to produce ethanol, $45 \%$ was used to feed livestock, and only $15 \%$ 551 was used for food and beverage [73].

552 Because of the present biofuel conditions (land, food problems and technological 553 barriers) and the limited reserves of energy, biofuel feedstock accounts for only a tiny 554 share of the biofuel supply in the global market. From 2008 to 2024, due to technical 555 innovations, there was and is expected to be a rapid development in biofuel 556 production with contributions from various biofuel types. Ethanol from grain and 557 from sugar cane are both expected to continue to grow, but the first will later become 558 irrelevant, while cane ethanol production will level off to below 100 Mtoe by 2025 . 559 Cellulosic ethanol became significant in 2015, and is expected to level off at 120 560 Mtoe by 2040. Biodiesel from seeds is expected to grow to less than 30 Mtoe by 2030 561 and then decrease [74]. Therefore, in the end, biofuel production innovations are 562 expected to gradually slow when the diffusion velocity addresses a specific level of 563 need, which indicates the need for a paradigm shift. 
The major problem with current biofuel production from biomass feedstock sources such as wheat, sugar beet, corn, straw, and wood is the availability of raw materials and the development trajectory. In this paper, a DAS was proposed, and then three stages in the biofuel production feedstock development were identified. By combining these results with paradigm theory, a BFDP was proposed, which included BFDP competition (first-generation biofuel in the first stage), BFDP diffusion (second-generation biofuel in the second stage), and BFDP shift (third-generation biofuel in the third stage).

At present there is a global debate over biofuels. For the scientific community, biofuel is a technological system that encompasses complex interactions at the local, national and global levels which can positively address rural poverty and economic development and negatively lead to dramatic land use changes, increasing food prices, decreasing food security and increased water use [75]. Further, the biofuel production diffusion velocity model showed that in 2014, diffusion velocity was estimated to be less than 1 , and biofuel production worldwide is expected to remain at around the same levels until 2030. Therefore, to maintain sustainable ecosystems and economic societies, a biofuel production feedstock shift is required, which points to a paradigm shift.

\subsubsection{Thoughts on the soft (energy) path}

The so-called soft path proposed by Amory Lovins was originally used to manage energy resources and the energy crisis in 1973 in the United States; a concept that has proved to be a great success in practice. Lovins coined the term soft energy path to 
587

588

589

590

591

592

593

594

595

596

597

598

599

600

601

602

603

604

605

606

607

608

describe an alternative future where energy efficiency and appropriate renewable energy sources steadily replace a centralized energy system based on fossil and nuclear fuels [76]. The soft energy path is called soft because it emphasizes policy support and any changes have only gentle, manageable impacts. The basic advantage of the soft energy path is that it is expected to result in a set of social impacts that are more desirable than those of the hard energy path.

In recent years, the study of the soft path has been concentrated on the management of water resources, as in the papers published in Nature and Science related to water resources management using the soft path [24, 77]. This concept was further refined by Brooks, again for water resources management leading to the development of a theory for water management and water demand management [78].

Lovins believed that the main energy decisions were always gradually implemented; therefore, a major shift can take decades. A major factor in the soft path strategy is the flexibility to avoid major infrastructure changes, so that infrastructure is fixed for decades for a specific supply mode [76]. Lovins developed a number of transition strategies to achieve the soft energy path [79], which referred to the rise of a major domestic biofuels industry to replace $25 \%$ of US oil demand, which could promote economic development in rural areas through the growing of biofuels plant material. Therefore, the soft path is also introduced here as part of the biofuels new path development.

Lovins stated that an energy path can be characterized as a complex, interactive set of mutually reinforcing, internally consistent features that together constitute an energy 
609

610

611

612

613

614

615

616

617

618

619

620

621

622

623

624

625

626

627 Paradigm shift, also called paradigm change, is the fifth and final step in the Kuhn

628

629

630

system; in effect, a sociotechnical system [80]. The main features and their interrelations were identified as follows:

1. A social context consisting of cultural values (e.g. preferences, policies) and associated institutions and organizations (e.g. economic, political, and legal).

2. A set of technological features (e.g. materials, fuels, processes, flows, skills).

3. A set of impacts related to society welfare.

From an overview of the soft energy notion, we focused on its defining features and on the social impact of the soft energy system. Lovins' original argument for soft energy remains the most influential and is by far the most detailed, systematic, and consistent of the many ideas offered by other soft energy advocates. The biofuel debate and the predicted incrementalism are the main identified problems, indicating that biofuel feedstock development requires a paradigm shift and a new path. Combined with Lovins’ soft path, an integrated system may be the best direction.

\subsubsection{Paradigm shift and its drivers}

Driven by Kuhn's seminal work on scientific revolutions, the word paradigm has been used to refer to a thought pattern in any scientific discipline [7]. A paradigm is a comprehensive model of understanding that provides viewpoints and rules to allow for an examination of the problems, and the development of possible solutions. Cycle [81] (shown in Fig. 9(a)). Once a single new paradigm is settled on by a few influential supporters, the paradigm change step begins. Here there is a transition from the old to the new paradigm, which then develops to maturity. Eventually, the old 
631

632

633 Therefore, rather than being an evolutionary process, the paradigm shift represents a

634 revolutionary transformation or metamorphosis from one mode of thinking to another.

635

636 scientific literature in the second half of the 20th century. However, the Kuhn Cycle

637 can also be applied to critical use knowledge with an evolutionary construction.

638 Therefore, it can be applied to model sustainable biofuel use.

639 The abstraction of the Kuhn Cycle frames the global environmental sustainability

640 problem as something that is part of a predictable system behavior pattern. The

641 biofuel production diffusion velocity model shows that the zero incremental is

642 predictable, and the Kuhn Cycle allows us to see that the next step is probably going

643 to be Model Revolution. This, however, should be avoided because historically large

644 changes in social governance models take a long time and are too often accompanied

645 by excessive amounts of violence, suffer ing, and unpredictability. Fortunately there is

646 a better way to bypass the Revolution step, and arrive at the next step, Paradigm

647 Change. This can be done by grafting the System Improvement Process onto the Kuhn

648 Cycle as shown in Fig. 9(b) [82], and then promoting biofuel to ensure the correct 649 direction is taken. 
651

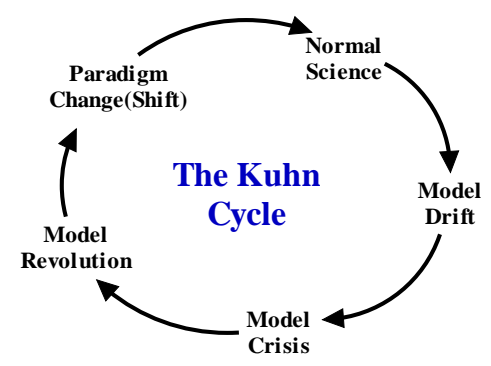

£" a£(

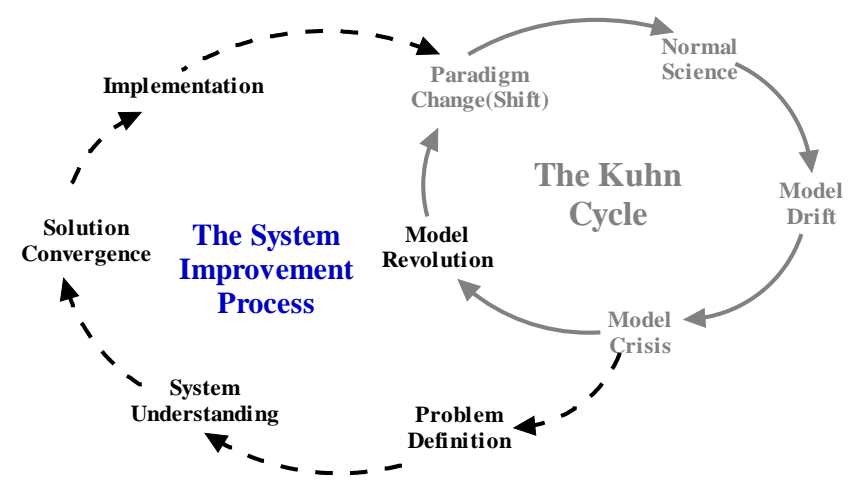

E" b£(C)

Fig. 9. The Kuhn Cycle and the System Improvement Process

The System Improvement Process is a simple, generic, highly analytical process designed to be applied to all complex social system problems. There are four main steps, as shown in the diagram; the first is to formally define the problem to be solved, which focuses all subsequent problems on the solution; the second is to understand system behavior, on which approximately $80 \%$ of the time should be spent so that the third step solution can be identified; the fourth step implements the solution.

Lovins’ research indicated that significant energy decisions are always gradually implemented, so it can take decades to achieve a major shift. However, soft path strategy is also flexible so as to avoid any major infrastructure changes in the specific supply mode. Lovin's discussion included the biofuel market and a proposed sociotechnical system to achieve the soft energy path, which in this paper is seen as part of the System Improvement Process. Therefore, the soft path is introduced to achieve the paradigm shift and to study the development of biofuels in the new path.

“soft path” complements the hard path through investment in decentralized facilities, and the development of efficient technologies, associated policies, and human capital. 
668

669

670

671

672

673

674

Compared with the hard path (centralized, inefficient, highly-technological energy supply methods), the soft path seeks to improve the management of sources rather than merely finding new technologies or sources $[13,83]$. The soft path attempts to look for innovations that are able to offer a marked improvement on present day approaches or provide an entirely new perspective [11].

Instead of moving away from supply-side solutions to meet demand (e.g. expanding physical infrastructure), it is necessary to focus on long-term, comprehensive management approaches that will ensure adequate resource quantities in the future. Therefore, a soft path strategy is proposed to sustainably manage resources now and into the future, which will eventually lead to a paradigm shift. Recent policy developments suggest that the traditional paradigm characterized by a sustained yield is in the process of being invalidated. While a new paradigm has been fully accepted, the emerging paradigm does appear to be based on two principles: ecosystem management and collaborative decision making. The best way to achieve a sustainable future is to develop decision-making processes, institutions, and technologies that emphasize both efficiency and conservation. The soft path supports the next "age" of resource management and is expected to play a key role in system improvement processes which would lead to a paradigm shift.

In the DAS tendency analysis, 'policy', 'management' and 'system' in Area M imply measurements on the soft path and the driving power to the next paradigm shift. The improved technological paradigm evolution with the soft path as the driver to the next paradigm is shown in Fig. 10. Competition and technological paradigm shifts in 
690

691

692

694

695

696

697

698

699

700

701

702

703

704

705

transportation and industrial production can be characterized by the introduction of a new emerging integrated system that penetrates existing business supply chains and competes for market share in accordance with the paradigm shift. Dynamic management, therefore, is required from researchers, governments and policy makers.

The biofuel policy aims to promote the use in transport of fuels made from biomass, as well as other renewable fuels. Biofuels provide the prospect of new economic opportunities for people in rural areas in oil importer and developing countries. The central policy of biofuel concerns job creation, greater efficiency in the general business environment, and protection of the environment.

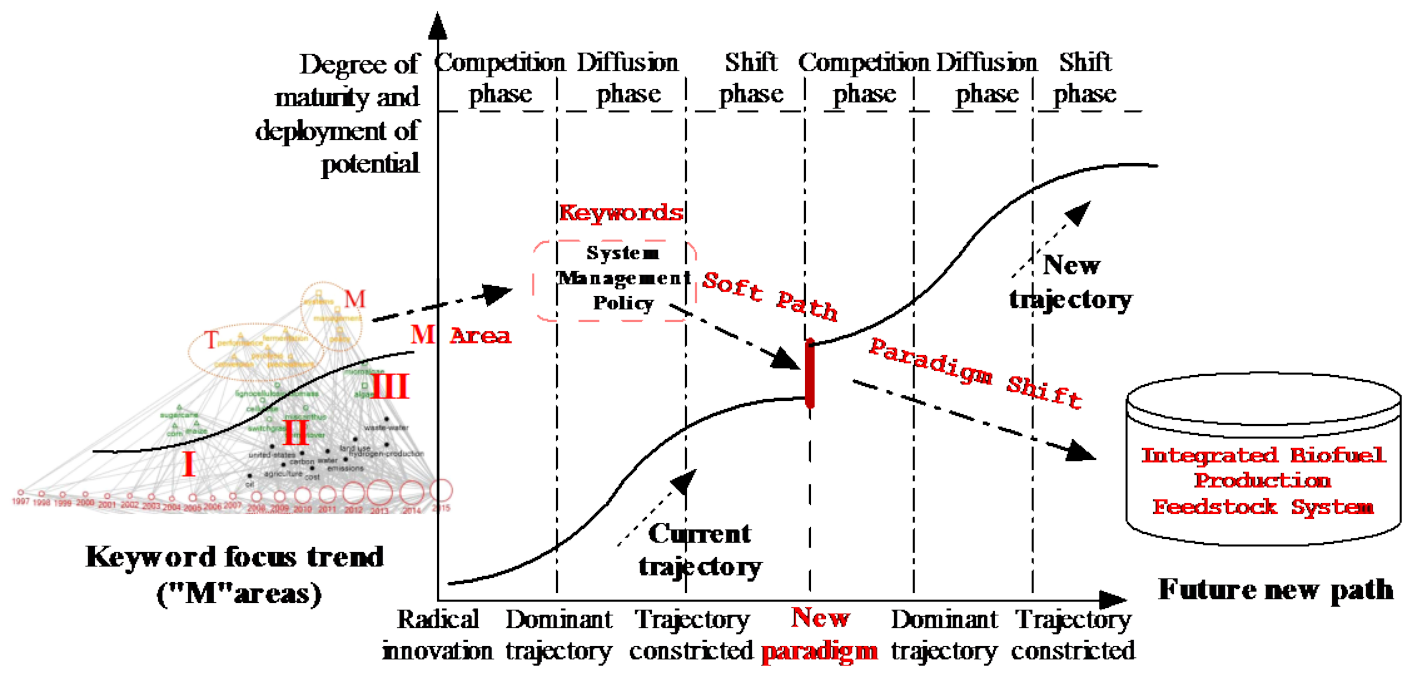

Life cycle of techno logical paradigm

Fig. 10. Paradigm shift combined with soft path according to technological paradigm

3.4.3. The proposed integrated system

Biofuel development has been generally seen as a promising way to enhance social, economic and environmental sustainability as it has a strong impact on critical issues such as climate change and energy security [84]. The central biofuel policy concerns job creation, greater efficiency in the general business environment and protection of 
the environment [85]. However, biofuel production feedstock has become a controversial issue in the biofuel industry. Theories on technological shifts and innovations appear to indicate that biofuel production feedstock is likely to move less towards disruptive innovations but instead focus on incremental innovations and economies of scale. Three kinds of mainstream feedstock have emerged according to the paradigm trajectory. Further, the above methods and discussions from the three BFDP stages, the biofuel production diffusion velocity model results, and the biofuel production background show there is going to be an urgent need for a paradigm shift in the near future as energy system applications are sought for a low-carbon society [77]. The soft path focuses on the management of biofuel sources.

Collaboration is required between governments, communities and private companies to achieve the sustainable development of biofuel sources rather than only focusing on supply. A rational application of technologies and economics, and decision-making at the right levels could improve the productive use of biofuel. Furthermore, in a biofuel industry context, government policies that may influence the competition between the food and energy market need to be developed. Therefore, instead of supply-based approaches, management and policies combined with the technology and resources can push for a paradigm shift that encompasses economic, ecological and social sustainability [78]. An "Integrated biofuel production feedstock system" is the next best "source" of new biofuel feedstock as it takes account of the environmental, technological, economic, institutional and cultural characteristics of biofuel production, as shown in Fig. 11. 


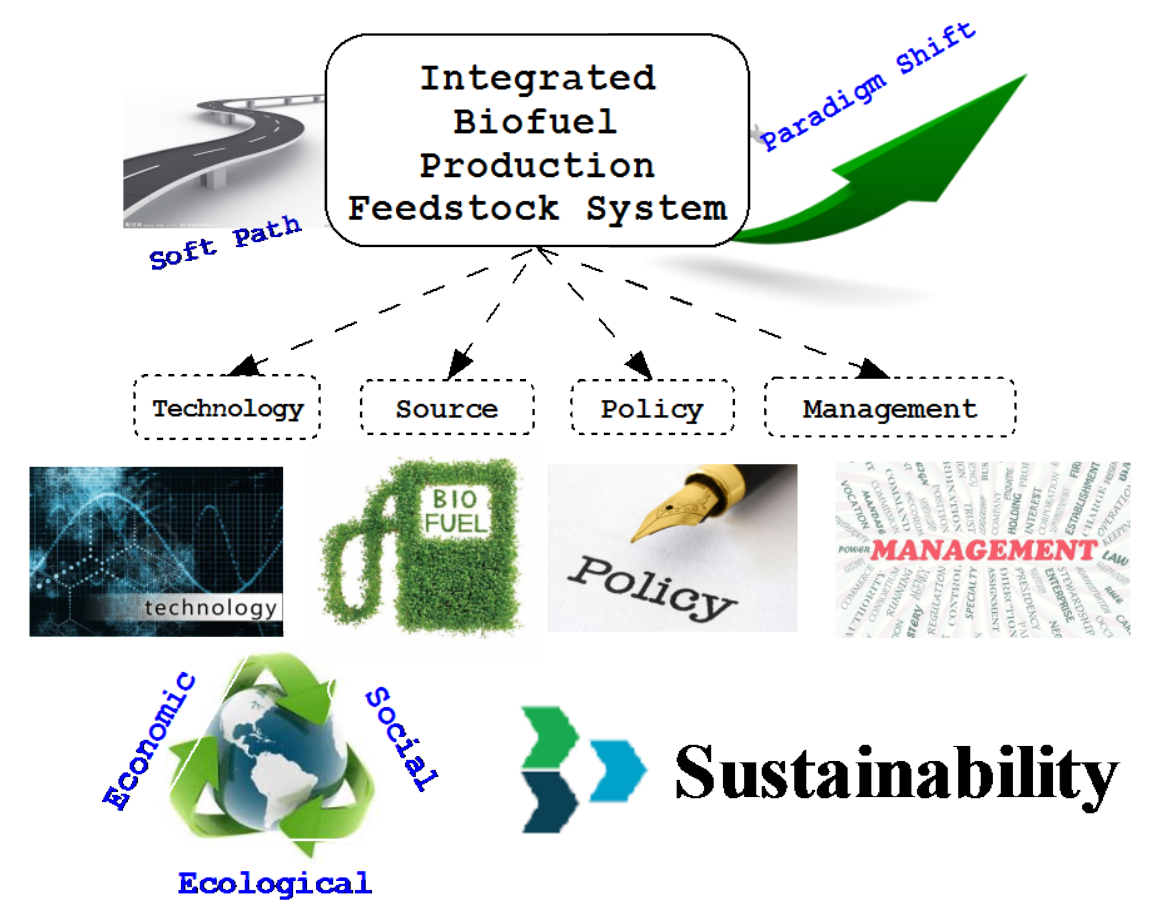

Fig. 11. "Integrated biofuel production feedstock system” structure

To achieve sustainable energy production, the potential of biofuel requires a long-term

731 view. New technologies, new sources and, most importantly, the management of these

732 and relevant policy frameworks from the soft path need to be enhanced to generate a

733 paradigm shift. Considerably more investment in research, development,

734 demonstrations, and deployment is needed to ensure that the future production of the

735 various biomass feedstock can be undertaken sustainably and can continue to play a

736 significant role in low-carbon, sustainable energy systems.

737 4. Conclusions

738 In this paper, we presented an innovative approach which combined technological 739 paradigm theory with literature mining to discover key areas and trends in biofuel 740 production feedstock. Using appropriate technology and software, a data analysis system (DAS) was developed with four modules to determine the relevant research 
742

743

744

745

746

747

748

749

750

751

752

753

754

755

foci. Despite significant research having been conducted, there has not yet been a paradigmatic framework for biofuel production feedstock development. Using the DAS, keyword focus trends were identified to assess the three distinct biofuel feedstock stages, which were in accordance with technological paradigm theory.

After combining paradigm theory with the feedstock development research findings, a biofuel feedstock development paradigm (BFDP) was proposed, which included; BFDP competition, BFDP diffusion, and BFDP shift. This paradigm framework gives a view of the current development of biofuel feedstock. Further, a biofuel production diffusion velocity model was proposed to simulate and predict biofuel production in the future. The analyses and results showed that biofuel production development has a similar trajectory to the BFDP, with the diffusion velocity estimated to be close to zero by 2030. Therefore, a paradigm shift is expected from the various biofuel feedstock contributions and the biofuel debates.

Pioneering the use of the soft path and combining it with the analyses results from the biofuel feedstock keywords foci, an "Integrated biofuel production feedstock system" was proposed as an approach for the paradigm shift, which has the potential to play a significant role in a low-carbon, sustainable future.

Acknowledgements

This research has been supported by the Key Program of NSFC (Grant No. 70831005) and the National Science Foundation for Distinguished Young Scholars, PR China (Grant No. 70425005). The authors would like to thank the anonymous referees for their insightful comments and suggestions to improve this paper, as well as the 
764

765

766

767

768

769

770

771

772

773

774

775

776

777

778

779

780

781

782

783

784

785

Uncertainty Decision-Making Laboratory of Sichuan University for helpful comments and discussion.

References

[1] A. Demirbas, Biomass resource facilities and biomass conversion processing for fuels and chemicals, Energy conversion and Management 42 (11) (2001) 1357-1378.

[2] A. Demirbas, Progress and recent trends in biofuels, Progress in energy and combustion science 33 (1) (2007) 1-18.

[3] L. Cozzi, World energy outlook 2011.

[4] D. Tilman, J. Hill, C. Lehman, Carbon-negative biofuels from low-input high-diversity grassland biomass, Science 314 (5805) (2006) 1598-1600.

[5] P. S. Nigam, A. Singh, Production of liquid biofuels from renewable resources, Progress in energy and combustion science 37 (1) (2011) 52-68.

[6] C. A. Cardona, O’. J. Sa'nchez, Fuel ethanol production: process design trends and integration opportunities, Bioresource technology 98 (12) (2007) 2415-2457.

[7] T. S. Kuhn, The structure of scientific revolutions, University of Chicago press, 2012.

[8] G. Dosi, Technological paradigms and technological trajectories: a suggested interpretation of the determinants and directions of technical change, Research policy 11 (3) (1982) 147-162.

[9] J. Van den Ende, W. Dolfsma, Technology-push, demand-pull and the shaping of technological paradigms-patterns in the development of computing technology, Journal of Evolutionary Economics 15 (1) (2005) 83-99. 
786

787

788

789

790

791

792

793

794

795

796

797

798

799

800

801

802

803

804

805

806

807

[10] J. Xu, L. Li, B. Zheng, Wind energy generation technological paradigm diffusion, Renewable and Sustainable Energy Reviews 59 (2016) 436-449.

[11] J. Xu, T. Ni, B. Zheng, Hydropower development trends from a technological paradigm perspective, Energy Conversion and Management 90 (2015) 195-206.

[12] B. Zheng, J. Xu, T. Ni, M. Li, Geothermal energy utilization trends from a technological paradigm perspective, Renewable Energy 77 (2015) 430-441.

[13] P. H. Gleick, Global freshwater resources: soft-path solutions for the 21st century, Science 302 (5650) (2003) 1524-1528.

[14] B. Gupta, S. Bhattacharya, Bibliometric approach towards mapping the dynamics of science and technology, DESIDOC Journal of Library \& Information Technology $24(1)$.

[15] F. Narin, Patent bibliometrics, Scientometrics 30 (1) (1994) 147-155.

[16] R. N. Kostoff, The use and misuse of citation analysis in research evaluation, Scientometrics 43 (1) (1998) 27-43.

[17] Y. Kajikawa, J. Yoshikawa, Y. Takeda, K. Matsushima, Tracking emerging technologies in energy research: Toward a roadmap for sustainable energy, Technological Forecasting and Social Change 75 (6) (2008) 771-782.

[18] Y. Kajikawa, Y. Takeda, Structure of research on biomass and bio-fuels: A citation-based approach, Technological Forecasting and Social Change 75 (9) (2008) 1349-1359.

[19] R. N. Kostoff, R. R. Schaller, Science and technology roadmaps, Engineering Management, IEEE Transactions on 48 (2) (2001) 132-143. 
808

809

810

811

812

813

814

815

816

817

818

819

820

821 [25] J. Webster, R. T. Watson, Analyzing the past to prepare for the future: Writing a, 822 MIS quarterly 26 (2) (2002) 13-23.

823

824

825

826

827

828

829

[20] G. Dijkema, P. Ferr̃ao, P. Herder, M. Heitor, Trends and opportunities framing innovation for sustainability in the learning society, Technological Forecasting and Social Change 73 (3) (2006) 215-227.

[21] B. Gupta, S. Bhattacharya, Bibliometric approach towards mapping the dynamics of science and technology, DESIDOC Journal of Library \& Information Technology $24(1)$

[22] C. Baldwin, J. Hughes, T. Hope, R. Jacoby, S. Ziebland, Ethics and dementia: mapping the literature by bibliometric analysis, International journal of geriatric psychiatry 18 (1) (2003) 41-54.

[23] Y. Tian, C. Wen, S. Hong, Global scientific production on gis research by bibliometric analysis from 1997 to 2006, Journal of Informetrics 2 (1) (2008) 65-74.

[24] B. De Bruijn, J. Martin, Getting to the (c) ore of knowledge: mining biomedical literature, International journal of medical informatics 67 (1) (2002) 7-18.

[26] M. Scherf, A. Epple, T. Werner, The next generation of literature analysis: integration of genomic analysis into text mining, Briefings in bioinformatics 6 (3) (2005) 287-297.

[27] G. Dosi, et al., The nature of the innovative process, Technical change and economic theory 2 (1988) 590-607.

[28] O. Kuusi, M. Meyer, Anticipating technological breakthroughs: Using bibliographic coupling to explore the nanotubes paradigm, Scientometrics 70 (3) 
830

831

832

833

834

835

836

837

838

839

840

841

842

843

844

845

846

847

848

849

850

851

(2007) 759-777.

[29] P. S. Meyer, J. W. Yung, J. H. Ausubel, A primer on logistic growth and substitution: the mathematics of the loglet lab software, Technological Forecasting and Social Change 61 (3) (1999) 247-271.

[30] P. A. Geroski, Models of technology diffusion, Research policy 29 (4) (2000) 603-625.

[31] M. A. Schilling, M. Esmundo, Technology s-curves in renewable energy alternatives: Analysis and implications for industry and government, Energy Policy 37 (5) (2009) 1767-1781.

[32] Y.-H. Chen, C.-Y. Chen, S.-C. Lee, Technology forecasting of new clean energy: The example of hydrogen energy and fuel cell, African Journal of Business Management 4 (7) (2010) 1372.

[33] T. Islam, N. Meade, The diffusion of successive generations of a technology: A more general model, Technological Forecasting and Social Change 56 (1) (1997) 49-60.

[34] R. N. Kostoff, H. J. Eberhart, D. R. Toothman, Hypersonic and supersonic flow roadmaps using biblio metrics and database tomography, Journal of the Association for Information Science and Technology 50 (5) (1999) 427.

[35] R. J. Dolan, A. P. Jeuland, Experience curves and dynamic demand models: Implications for optimal pricing strategies, The Journal of Marketing (1981) 52-62.

[36] Z. Griliches, Hybrid corn: An exploration in the economics of technological change, Econometrica, Journal of the Econometric Society (1957) 501-522. 
852

853

[37] E. Mansfield, Technical change and the rate of imitation, Econometrica: Journal of the Econometric Society (1961) 741-766.

[38] M. Karshenas, P. L. Stoneman, Rank, stock, order, and epidemic effects in the diffusion of new process technologies: An empirical model, The RAND Journal of Economics (1993) 503-528.

[39] H. Gatignon, J. Eliashberg, T. S. Robertson, Modeling multinational diffusion patterns: An efficient methodology, Marketing Science 8 (3) (1989) 231-247.

[40] E. M. Rogers, Diffusion of innovations, Simon and Schuster, 2010.

[41] BP., BP statistical review of world energy, BP, 2015.

[42] M. Willinger, E. Zuscovitch, Efficience, irr'eversibilit'es et constitution des technologies, Revue d’'economie industrielle 65 (1) (1993) 7-22.

[43] A. Ghosh, S. Khanra, M. Mondal, G. Halder, O. Tiwari, S. Saini, T. K. Bhowmick, K. Gayen, Progress toward isolation of strains and genetically engineered strains of microalgae for production of biofuel and other value added chemicals: A review, Energy Conversion and Management 113 (2016) 104-118.

[44] R. U. Ayres, Barriers and breakthroughs: an expanding frontiers model of the technology-industry life cycle, Technovation 7 (2) (1988) 87-115.

[45] R. Sims, M. Taylor, J. Saddler, W. Mabee, From 1st-to 2nd-generation biofuel technologies: an overview of current industry and rd\&d activities, International Energy Agency (2008) 16-20.

[46] J. D. Stephen, W. E. Mabee, J. N. Saddler, Will second-generation ethanol be able to compete with first-generation ethanol? opportunities for cost reduction, 
874

875

876

877

878

879

880

881

882

883

884

885

886

887

888

889

890

891

892

893

894

895

Biofuels, Bioproducts and Biorefining 6 (2) (2012) 159 - 176.

[47] J. Fargione, J. Hill, D. Tilman, S. Polasky, P. Hawthorne, Land clearing and the biofuel carbon debt, Science 319 (5867) (2008) 1235-1238.

[48] T. Searchinger, R. Heimlich, R. A. Houghton, F. Dong, A. Elobeid, J. Fabiosa, S. Tokgoz, D. Hayes, T.-H. Yu, Use of us croplands for biofuels increases greenhouse gases through emissions from land-use change, Science 319 (5867) (2008) $1238-1240$.

[49] R. Doornbosch, R. Steenblik, Biofuels: Is the cure worse than the disease?, Revista Virtual REDESMA 2 (2008) 63.

[50] R. E. Sims, W. Mabee, J. N. Saddler, M. Taylor, An overview of second generation biofuel technologies, Bioresource technology 101 (6) (2010) 1570-1580.

[51] A. Petersen, R. Melamu, J. Knoetze, J. G*orgens, Comparison of second-generation processes for the conversion of sugarcane bagasse to liquid biofuels in terms of energy efficiency, pinch point analysis and life cycle analysis, Energy Conversion and Management 91 (2015) 292-301.

[52] A. Nagamatsu, C. Watanabe, K. L. Shum, Diffusion trajectory of self-propagating innovations interacting with institutionsincorporation of multi-factors learning function to model pv diffusion in japan, Energy Policy 34 (4) (2006) 411-421.

[53] Q. Kang, L. Appels, T. Tan, R. Dewil, Bioethanol from lignocellulosic biomass: current findings determine research priorities, The Scientific World Journal 2014.

[54] J. Ohlrogge, D. Allen, B. Berguson, D. DellaPenna, Y. Shachar-Hill, S. Stymne, Driving on biomass, Science 324 (5930) (2009) 1019. 
896

897

898

899

900

901

902

903

904

905

906

907

908

909

910

911

912

913

914

915

916

917

[55] H. Londo, E. Deurwaarder, E. Van Thuijl, Review of eu biofuels directive public consultation exercisesummary of the responses, Energy Research Centre of the Netherlands, Amsterdam.

[56] D. Graham-Rowe, Agriculture: Beyond food versus fuel, Nature 474 (7352) (2011) S6-S8.

[57] F. Chen, R. A. Dixon, Lignin modification improves fermentable sugar yields for biofuel production, Nature biotechnology 25 (7) (2007) 759-761.

[58] B. Kiran, R. Kumar, D. Deshmukh, Perspectives of microalgal biofuels as a renewable source of energy, Energy Conversion and Management 88 (2014) $1228-1244$.

[59] C. Christensen, The innovator's dilemma: when new technologies cause great firms to fail, Harvard Business Review Press, 2013.

[60] H. Dalgleish, I. Foster, 137 cs losses from a loamy surface water gleyed soil (inceptisol); a laboratory simulation experiment, Catena 26 (3) (1996) 227-245.

[61] D. Thr“an, T. Seidenberger, J. Zeddies, R. Offermann, Global biomass potentialsresources, drivers and scenario results, Energy for sustainable development 14 (3) (2010) 200-205.

[62] A. J. Wargacki, E. Leonard, M. N. Win, D. D. Regitsky, C. N. S. Santos, P. B. Kim, S. R. Cooper, R. M. Raisner, A. Herman, A. B. Sivitz, et al., An engineered microbial platform for direct biofuel production from brown macroalgae, Science 335 (6066) (2012) 308-313.

[63] J. G. Canadell, E. D. Schulze, Global potential of biospheric carbon management 
918

919

920

921

922

923

924

925

926

927

928

929

930

931

932

933

934

935

936

937

938

939

for climate mitigation, Nature communications (2014) 5.

[64] M. K. Lam, K. T. Lee, Microalgae biofuels: a critical review of issues, problems and the way forward, Biotechnology advances 30 (3) (2012) 673-690.

[65] C. Schubert, Can biofuels finally take center stage? Nature biotechnology 24 (7) (2006) 777-784.

[66] Y. Zhou, L. Schideman, G. Yu, Y. Zhang, A synergistic combination of algal wastewater treatment and hydrothermal biofuel production maximized by nutrient and carbon recycling, Energy \& Environmental Science 6 (12) (2013) 3765-3779.

[67] A. F. Clarens, E. P. Resurreccion, M. A. White, L. M. Colosi, Environmental life cycle comparison of algae to other bioenergy feedstocks, Environmental science \& technology 44 (5) (2010) 1813-1819.

[68] M. Enquist-Newman, A. M. E. Faust, D. D. Bravo, C. N. S. Santos, R. M. Raisner, A. Hanel, P. Sarvabhowman, C. Le, D. D. Regitsky, S. R. Cooper, et al., Efficient ethanol production from brown macroalgae sugars by a synthetic yeast platform, Nature 505 (7482) (2014) 239-243.

[69] S. Kim, B. E. Dale, Global potential bioethanol production from wasted crops and crop residues, Biomass and Bioenergy 26 (4) (2004) 361-375.

[70] M. Demirbas, M. Balat, Recent advances on the production and utilization trends of bio-fuels: a global perspective, Energy Conversion and Management 47 (15) (2006) 2371-2381.

[71] M. Joyce, Biofuels production drives growth in overall biomass energy use over past decade (2014). 
940

941

942

943 Ames.

944

945

946

947

948

949

950

951

952

953

954

955

956

957

958

959

960

961

16). and.

[72] S. Irwin, The profitability of biodiesel production in 2014, farmdoc daily 5 (5):

[73] R. Wisner, Ethanol usage projections \& corn balance sheet, Iowa State University,

[74] F. Galembeck, Synergy in food, fuels and materials production from biomass,

Energy \& Environmental Science 3 (4) (2010) 393-399.

[75] W. Gerbens-Leenes, A. Y. Hoekstra, The water footprint of sweeteners and bio-ethanol, Environment international 40 (2012) 202-211.

[76] A. B. Lovins, Soft energy paths: Toward a durable peace.

[77] T. Nakata, D. Silva, M. Rodionov, Application of energy system models for designing a low-carbon society, Progress in Energy and Combustion Science 37 (4) (2011) 462-502.

[78] D. Streimikiene, G. `Sivickas, The eu sustainable energy policy indicators framework, Environment International 34 (8) (2008) 1227-1240.

[79] A. B. Lovins, E. K. Datta, Winning the oil endgame, Innovations for Profits, Jobs

[80] D. E. Morrison, D. G. Lodwick, The social impacts of soft and hard energy systems: The lovins' claims as a social science challenge, Annual Review of Energy 6 (1) (1981) 357-378.

[81] Thwink.org, The kuhn cycle (2014).

[82] Thwink.org, A model in crisis: Can civilization bypass the model revolution step or not? (2014). 
962 [83] P. H. Gleick, Water management: Soft water paths, Nature 418 (6896) (2002)

$963 \quad 373-373$.

964 [84] A. Demirbas, Biofuels securing the planets future energy needs, Energy 965 Conversion and Management 50 (9) (2009) 2239-2249.

966 [85] A. Demirbas, Biofuels sources, biofuel policy, biofuel economy and global 967 biofuel projections, Energy conversion and management 49 (8) (2008) 2106-2116. 33 